\title{
Evaluation and Prediction Analysis of 3- and 5-Year Survival Rates of Patients with Cecal Adenocarcinoma Based on Period Analysis
}

\author{
Zi'an Shao ${ }^{1,2, *}$ \\ Shuai Zheng ${ }^{3, *}$ \\ Chong Chen ${ }^{3}$ \\ Jun Lyu (D) ${ }^{2}$
}

'The First School of Clinical Medicine, Southern Medical University, Guangzhou, Guangdong Province, People's Republic of China; ${ }^{2}$ Department of Clinical Research, The First Affiliated Hospital of Jinan University, Guangzhou, Guangdong Province, People's Republic of China; ${ }^{3}$ School of Public Health, Shaanxi University of Chinese Medicine, Xianyang, Shaanxi Province, People's Republic of China

*These authors contributed equally to this work
Correspondence: Jun Lyu Department of Clinical Research, The First Affiliated Hospital of Jinan University, Guangzhou, 51 0630, People's Republic of China

Tel +86-13379060I67

Email lyujun2020@jnu.edu.cn
Background: Cecal adenocarcinoma has a high degree of malignancy and poor prognosis, thereby bringing serious disease burden to patients. The long-term survival rate of patients with cecal adenocarcinoma deserves us to explore more deeply. In addition, appropriate methods that evaluate the survival outcome of cecal adenocarcinoma are few.

Methods: This study used the data provided by the Surveillance, Epidemiology, and End Results (SEER) database to evaluate and predict the survival rates of patients with cecal adenocarcinoma from 2002 to 2016 and from 2017 to 2021, respectively. The cohort of population taken are all older than 20 years old, which is from National Cancer Institute. The period analysis was used to check the data in the SEER database. Reliable results could be obtained using period analysis, which provided important information for prevention and treatment strategies.

Results: From 2002 to 2016, the relative survival rate of patients with cecal adenocarcinoma increased yearly. Compared with those in previous 15 years, the relative survival rate between 2017 and 2021 still increased but to a low extent. The relative survival rates of patients with cecal adenocarcinoma were remarkably different in terms of age, sex, race, differentiation grade, stages, and socioeconomic status. Even if there is a significant improvement, the survival rate of patients with distant-stage cancer is at a very low level.

Conclusion: Understanding the survival rate of patients with cecal adenocarcinoma in the past 15 years is helpful in predicting the future trend and providing basic data and scientific basis to evaluate the harm of cecal adenocarcinoma to patients' health, prepare cancer prevention plans, and evaluate the effect of cancer prevention and treatment by exploring the differences in survival rate corresponding to different ages, sexes, races, differentiation grades, stages, and socioeconomic status.

Keywords: cecal adenocarcinoma, SEER, period analysis, survival rates

\section{Introduction}

Cecal adenocarcinoma is a common malignant tumor with high mortality. Exploring the long-term survival rate of cecal adenocarcinoma can help us to further understand this malignant tumor. In the United States, colorectal cancer is the second major cause of cancer death. In 2020, about 147,950 patients are diagnosed with colorectal cancer in the United States, of which 53,200 have died. ${ }^{1}$ Moreover, colorectal cancer is the third most common cancer in the Western Hemisphere. ${ }^{2}$ Age, race, differentiation grade, socioeconomic status, and other factors affect the survival rate of colorectal cancer. ${ }^{3}$ Similarly, we can explore 
the effect of these factors on patients with cecal adenocarcinoma. ${ }^{2,4}$ In addition, stage is an important factor affecting the long-term survival rate of colorectal cancer. The prognosis basically depends on the tumor stage at the time of initial diagnosis. ${ }^{5}$ Cecal adenocarcinoma is an important part of colorectal cancer and accounts for about $20 \%$ of colorectal cancer. ${ }^{6}$ Right-sided colorectal cancer includes cecal adenocarcinoma, which shows different clinical features of left-sided colorectal cancer. In another cohort study, the prognosis of stage I and II tumors in right-sided colorectal cancer patients was significantly better than that in left-sided colorectal cancer patients. However, compared with patients with left-sided colorectal cancer, patients with right-sided colorectal cancer have poorer prognosis in advanced stage (stage III and IV) and higher recurrence rate after resection. ${ }^{7}$ However, the population-based assessment of the survival rate of cecal adenocarcinoma through period analysis is not available.

In recent years, period analysis has been gradually used to evaluate tumor survival. The model-based period analysis can predict tumor survival in the next few years. This study uses period analysis to evaluate the long-term survival rate of patients with cecal adenocarcinoma in the Surveillance, Epidemiology, and End Results (SEER) database from 2002 to 2016 and provide data support for the prevention and treatment of cecal adenocarcinoma. ${ }^{8}$

\section{Materials and Methods}

\section{Data Source}

The data in this paper were obtained from the IncidenceSEER 18 Regs Research Data + Hurricane Katrina Impacted Louisiana Cases, Nov 2018 Sub (1975-2016) in the SEER database, which was submitted to the SEER database in November 2018. The SEER database has a high-quality population-based cancer reporting system, which contains demographic data, tumor-related data, and socioeconomic characteristics. ${ }^{9}$ The data of patients with cecal adenocarcinoma from 2002 to 2016 were extracted using the SEER*Stat software (version 8.3.9). The inclusion criteria were as follows: (1) age of 20-100 years; (2) cecum as the primary site of the tumor and anatomical code of C18.0 according to the third edition of International Oncology Disease Analysis (International Classification of Disease for Oncology, ICD-O-3); and (3) adenocarcinoma pathological type (morphological code M814-M838), as confirmed by histopathology. The exclusion criteria were as follows: (1) incomplete pathological information, (2) follow-up time of 0, (3) unknown family economic status, and (4) cecal adenocarcinoma diagnosed by autopsy or death certificate.

All procedures performed in the present study were in accordance with the principles outlined in the 1964 Helsinki Declaration and its later amendments. This study was exempted from obtaining informed consents and review and approval by the institutional research committee of the First Clinical Medical College of Southern Medical University because SEER research data is publicly available and all patient data are deidentified.

\section{Data Sorting}

The indicators included in this study were diagnosis age, sex, race, socioeconomic status, differentiation grade, stages, diagnosis year, diagnosis month, last follow-up year and month, and survival status. Among these indicators, the year and month of the last follow-up were determined by the year of diagnosis, month of diagnosis, and time of follow-up. Socioeconomic status was based on the family poverty rate of patients, which was the percentage of households living below the poverty line in the region in 2013-2017. In accordance with the quartile distance of the family poverty rate, patients were divided into four groups: from high-income $(<5.34 \%)$, low-poverty $(\leq$ $5.34 \%$ and $<7.70 \%$ ), middle-poverty $(\leq 7.70$ and $<$ $12.69)$, and high-poverty $(\geq 12.69)$ areas. In this paper, the time of diagnosis was divided into three independent observation periods, ie, 2002-2006, 2007-2011, and 2012-2016. Races included whites, blacks, and other races (American Indian/AK Native, and Asian/Pacific Islander). Diagnostic ages of 20-24, 25-29, 30-34, 3539 , and 40-44 years were classified into the $<45$-year group. There are too few patients with carcinoma in situ, so we only discuss carcinoma which is localized-stage, regional-stage or distant-stage.

\section{Statistical Analysis}

In the population-based cancer surveillance, the relative survival is often reported as absolute or alternative absolute survival. ${ }^{10,11}$ The relative survival was the ratio of observed survival to the expected survival and adjusted for other causes of death, such as sex, age, and date. ${ }^{11,12}$ The relative survival rate could be expressed as: 


$$
R_{i}=\frac{\overline{S_{k}}}{S_{k}^{*}}
$$

When calculating the 5-year relative survival rate, $\mathrm{k}$ is 5 in the above formula and $S_{k}^{*}$ represent the observed and expected survival rates, respectively. The expected survival rate is derived from the life expectancy table stratified in accordance with the age and calendar year issued by the Centers for Disease Control and Prevention of the United States. ${ }^{13}$ The expected survival rate was calculated using the Ederer II method. ${ }^{11}$

On the basis of period analysis, a generalized linear model was established to estimate the survival rate of patients with tumor. In this study, the relative survival rates of patients in 2002-2006, 2007-2011, and 20122016 were estimated by period analysis, and the 3 - and 5 -year relative survival rates of diagnosed patients from 2017 to 2021 were predicted. The above calculation and analysis processes were completed using the PeriodR package.

\section{Results}

Cecal adenocarcinoma cases registered in the SEER database during the three observation periods are listed in Table 1. From 2002 to 2016, 63,263 patients with cecal adenocarcinoma were included in this study. The age distribution showed that nearly half of the people were over 75 years and that the number of people under 50 years was relatively small. In terms of gender, the number of women was slightly higher than that of men. The number of cases varied remarkably in terms of race, as shown by most patients being whites. From the point of view of tumor differentiation, the main patient was grade I and II cecal adenocarcinoma, ie, moderately differentiated. However, the number of patients with grade III and IV cecal adenocarcinoma was low. In terms of socioeconomic status, the distribution of the population was relatively balanced, in which relatively few people were in high-income areas. The distribution of the population in the three observation periods was relatively stable in terms of age, sex, race, differentiation grade, stages, and socioeconomic status. The number of cases in each category was more than 500 .

The 3- and 5-year survival rates of cecal adenocarcinoma are shown in Table 2, and trends are presented in Figures 1 and 2. During the above consecutive observation periods, all survival rates showed an upward trend. With increased age, the survival rate of patients decreased. The declines of 3- and 5-year survival rates were high in
Table I 2002-2016 Basic Situation of Cecal Adenocarcinoma Incidence

\begin{tabular}{|c|c|c|c|}
\hline Variable & $\begin{array}{l}2002-2006 \\
n(\%)\end{array}$ & $\begin{array}{l}2007-201 \text { I } \\
\text { n (\%) }\end{array}$ & $\begin{array}{l}2012-2016 \\
n(\%)\end{array}$ \\
\hline All & 20,244 & 21,319 & 21,700 \\
\hline $\begin{array}{l}\text { Diagnosis age } \\
<45 \\
45-49 \\
50-49 \\
55-59 \\
60-64 \\
65-74 \\
\geq 75\end{array}$ & $\begin{array}{l}592(2.9) \\
665(3.3)) \\
1310(6.5) \\
1679(8.3) \\
2111(10.4) \\
5509(27.2) \\
8378(41.4)\end{array}$ & $\begin{array}{l}610(2.9) \\
620(2.9) \\
1243(5.8) \\
1680(7.9) \\
2154(10.1) \\
5406(25.4) \\
9606(45.1)\end{array}$ & $\begin{array}{l}566(2.6) \\
583(2.7) \\
1059(4.9) \\
1503(6.9) \\
1950(9.0) \\
5392(24.8) \\
10,717(49.2)\end{array}$ \\
\hline $\begin{array}{l}\text { Sex } \\
\text { Male } \\
\text { Female }\end{array}$ & $\begin{array}{l}9209(45.5) \\
11,035(54.5)\end{array}$ & $\begin{array}{l}9442(44.3) \\
11,877(55.7)\end{array}$ & $\begin{array}{l}973 \mid(44.7) \\
\mid 2,039(55.3)\end{array}$ \\
\hline $\begin{array}{l}\text { Race } \\
\text { White } \\
\text { Black } \\
\text { Other races }\end{array}$ & $\begin{array}{l}16,268(80.4) \\
274 \mid(\mid 3.5) \\
I 235(6.1)\end{array}$ & $\begin{array}{l}17,359(8 \mid .4) \\
2806(\mid 3.2) \\
I I 54(5.4)\end{array}$ & $\begin{array}{l}I 8, I 23(83.2) \\
262 \mid(\mid 2.0) \\
1026(4.7)\end{array}$ \\
\hline $\begin{array}{l}\text { Socioeconomic } \\
\text { status } \\
\text { Rich } \\
\text { Low poverty } \\
\text { Medium poverty } \\
\text { High poverty }\end{array}$ & $\begin{array}{l}1260(6.2) \\
4900(24.2) \\
6765(33.4) \\
7319(36.2)\end{array}$ & $\begin{array}{l}1334(6.3) \\
5250(24.6) \\
7108(33.3) \\
7627(35.8)\end{array}$ & $\begin{array}{l}1460(6.7) \\
5398(24.8) \\
7 \mid 28(32.4) \\
7784(35.8)\end{array}$ \\
\hline $\begin{array}{l}\text { Grade } \\
\text { GI/G2 } \\
\text { G3/G4 }\end{array}$ & $\begin{array}{l}15,707(77.6) \\
4537(22.4)\end{array}$ & $\begin{array}{l}16,183(75.9) \\
5136(24.1)\end{array}$ & $\begin{array}{l}16,400(75.3) \\
5370(24.7)\end{array}$ \\
\hline $\begin{array}{l}\text { Stage } \\
\text { Localized } \\
\text { Regional } \\
\text { Distant }\end{array}$ & $\begin{array}{l}7878(38.9) \\
8588(42.4) \\
3778(18.7)\end{array}$ & $\begin{array}{l}8505(39.9) \\
8827(41.4) \\
3987(18.7)\end{array}$ & $\begin{array}{l}8403(38.6) \\
9286(42.7) \\
4081(18.7)\end{array}$ \\
\hline
\end{tabular}

Note: Not all columns round to $100 \%$ due to rounding.

patients $\geq 75$ years old. Overall, the survival rate of women was slightly higher than that of men. The generalized linear model predicted that the 3- and 5-year survival rates of all patients with cecal adenocarcinoma from 2017 to 2021 were $66.56 \%$ and $57.22 \%$, respectively. The 3 and 5-year survival rates of male patients with cecal adenocarcinoma were $66.27 \%$ and $56.51 \%$, respectively, whereas those of female patients with cecal adenocarcinoma were $66.75 \%$ and $57.71 \%$, respectively.

The 3- and 5-year survival rates of patients with cecal adenocarcinoma of different races and socioeconomic status are detailed in Table 3, and the changing trends are shown in Figures 3 and 4. From 2012 to 2016, the 3- and 
Table 2 3-Year and 5-Year Relative Survival Rates of Cecal Adenocarcinoma Patients According to Diagnosis Age and Sex from 2002 to 2016 and Forecast of the Relative Survival Rates of Cecal Adenocarcinoma Patients According to Diagnosis Age and Sex from 2017 to 2021

\begin{tabular}{|l|l|l|l|l|}
\hline & $\begin{array}{l}2002- \\
2006\end{array}$ & $\begin{array}{l}2007- \\
2011\end{array}$ & $\begin{array}{l}2012- \\
2016\end{array}$ & $\begin{array}{l}2017- \\
2021\end{array}$ \\
\hline 3 years survival rates & & & & \\
All & $60.9 \pm 0.3$ & $63.7 \pm 0.3$ & $65.3 \pm 0.3$ & 66.56 \\
Male & $59.8 \pm 0.5$ & $63.7 \pm 0.5$ & $64.8 \pm 0.5$ & 66.27 \\
Female & $61.9 \pm 0.4$ & $63.7 \pm 0.4$ & $65.6 \pm 0.5$ & 66.75 \\
$<45$ & $74.5 \pm 1.9$ & $74.9 \pm 1.8$ & $74.2 \pm 1.9$ & 75.36 \\
$45-49$ & $67.9 \pm 2.0$ & $71.7 \pm 1.8$ & $72.1 \pm 1.8$ & 75.11 \\
$50-54$ & $71.8 \pm 1.4$ & $74.0 \pm 1.3$ & $76.9 \pm 1.2$ & 77.69 \\
$55-59$ & $68.6 \pm 1.2$ & $72.6 \pm 1.1$ & $69.5 \pm 1.1$ & 71.44 \\
$60-64$ & $67.8 \pm 1.1$ & $70.6 \pm 1.0$ & $71.1 \pm 1.0$ & 72.02 \\
$65-74$ & $65.7 \pm 0.6$ & $63.3 \pm 0.6$ & $70.9 \pm 0.6$ & 72.45 \\
$\geq 75$ & $54.1 \pm 0.5$ & $55.3 \pm 0.5$ & $56.6 \pm 0.5$ & 56.98 \\
\hline 5 years survival rates & & & & \\
All & $49.4 \pm 0.4$ & $52.9 \pm 0.4$ & $54.3 \pm 0.4$ & 57.22 \\
Male & $48.2 \pm 0.5$ & $52.0 \pm 0.5$ & $53.4 \pm 0.5$ & 56.51 \\
Female & $50.4 \pm 0.5$ & $53.7 \pm 0.5$ & $55.0 \pm 0.5$ & 57.71 \\
$<45$ & $66.9 \pm 2.2$ & $68.0 \pm 1.9$ & $66.5 \pm 2.0$ & 66.76 \\
$45-49$ & $58.1 \pm 2.2$ & $64.8 \pm 2.0$ & $63.1 \pm 1.9$ & 67.18 \\
$50-54$ & $62.1 \pm 1.6$ & $66.5 \pm 1.4$ & $67.0 \pm 1.3$ & 70.34 \\
$55-59$ & $59.9 \pm 1.4$ & $63.5 \pm 1.2$ & $60.4 \pm 1.2$ & 61.80 \\
$60-64$ & $58.5 \pm 1.2$ & $61.8 \pm 1.1$ & $61.4 \pm 1.1$ & 63.35 \\
$65-74$ & $55.8 \pm 0.7$ & $59.5 \pm 0.7$ & $61.3 \pm 0.7$ & 64.41 \\
$\geq 75$ & $40.7 \pm 0.6$ & $42.6 \pm 0.5$ & $43.9 \pm 0.5$ & 45.72 \\
\hline
\end{tabular}

Note: Survival rates is relative survival rates; data are means \pm standard error of the mean.

5-year survival rates of black patients were lower than those of white patients and other races. Compared with 2002-2006, the 3-year and 5-year survival rates of all races increased in 2012-2016. A low socioeconomic status indicated low survival rate. The survival rate of people with different socioeconomic conditions increased. The generalized linear model predicted that the 3- and 5-year survival rates of Caucasian patients with cecal adenocarcinoma from 2017 to 2021 were $66.70 \%$ and 57.24\%, respectively. The 3- and 5-year survival rates of black patients with cecal adenocarcinoma were $63.99 \%$ and $54.87 \%$, respectively, and those of patients with cecal adenocarcinoma of other races were $69.46 \%$ and $61.28 \%$, respectively. The 3- and 5-year survival rates of patients with cecal adenocarcinoma from high-income areas were $69.97 \%$ and $61.28 \%$, respectively, whereas those from low-poverty areas were $69.27 \%$ and $60.82 \%$, respectively. The 3- and 5-year survival rates of patients with cecal adenocarcinoma in middle-poverty and were $66.85 \%$ and
$56.98 \%$, respectively, whereas those from high-poverty areas were $63.85 \%$ and $54.29 \%$, respectively.

The 3- and 5-year survival rates of patients with cecal adenocarcinoma of different differentiation grades are detailed in Table 4, and the changing trend can be seen in Figure 5. From 2012 to 2016, a high differentiation grade resulted in low survival rate. Compared with 2002-2006, the 3- and 5-year survival rates of all grades in 2012-2016 increased. From 2017 to 2021, the generalized linear model predicted that the 3- and 5-year survival rates were $71.34 \%$ and $61.38 \%$, respectively, in patients with grade I and grade II cecal adenocarcinoma; $50.76 \%$ and $42.72 \%$, respectively, in patients with grade III and grade IV cecal adenocarcinoma.

The 3- and 5-year survival rates of patients with cecal adenocarcinoma of different stages are detailed in Table 4, and the changing trends are shown in Figure 6. From 2002 to 2016, the survival rate of patients with distant-stage cancer was at a very low level, and the which was no more than 25\%. From 2017 to 2021, the generalized linear model predicted that the 3- and 5-year survival rates were $84.33 \%$ and $75.93 \%$, respectively, in patients with localized-stage cecal adenocarcinoma. $69.68 \%$ and $58.53 \%$, respectively, in patients with regional-stage cecal adenocarcinoma. $25.07 \%$ and $15.11 \%$, respectively, in patients with distant-stage cecal adenocarcinoma.

\section{Discussion}

According to the global estimate of 19,292,789 new cases of cancer published by International Agency for Research on Cancer, colorectal cancer is the 3rd and 2nd major causes of death in men and women, respectively. Studies showed that the incidence of right colorectal cancer has increased, with the largest increase observed in cecal adenocarcinoma. ${ }^{14-16}$ Thus, the accurate prediction of the survival rate of patients with cecal adenocarcinoma is important for our treatment and care of patients. ${ }^{17}$

We demonstrate that the relative survival rate of cecal adenocarcinoma is gradually increasing during the three observation periods from the first five years to the third five years and in the forecast period of 2017-2021. Compared with 2002-2006, 2017-2021 has shown increases in the 3- and 5-year survival rates by $6.47 \%$ and $7.82 \%$, respectively. During the 15 years of analysis, the survival rate of patients is affected by the patient's age, sex, race, differentiation grade, stages, and socioeconomic status at varying degrees. In patients who are female, older, and have higher grade differentiation, the prognosis 


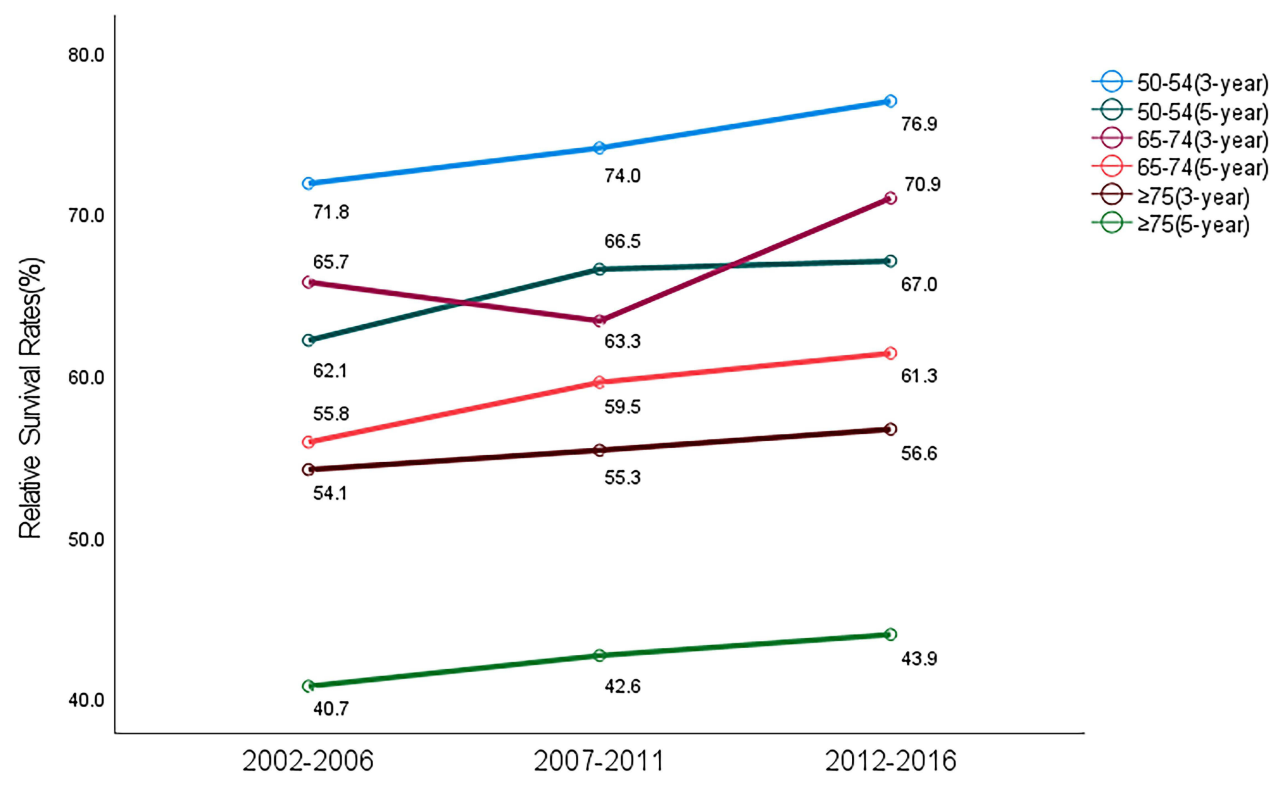

Figure I Trend and prediction of survival rate in patients with cecal adenocarcinoma of different ages.

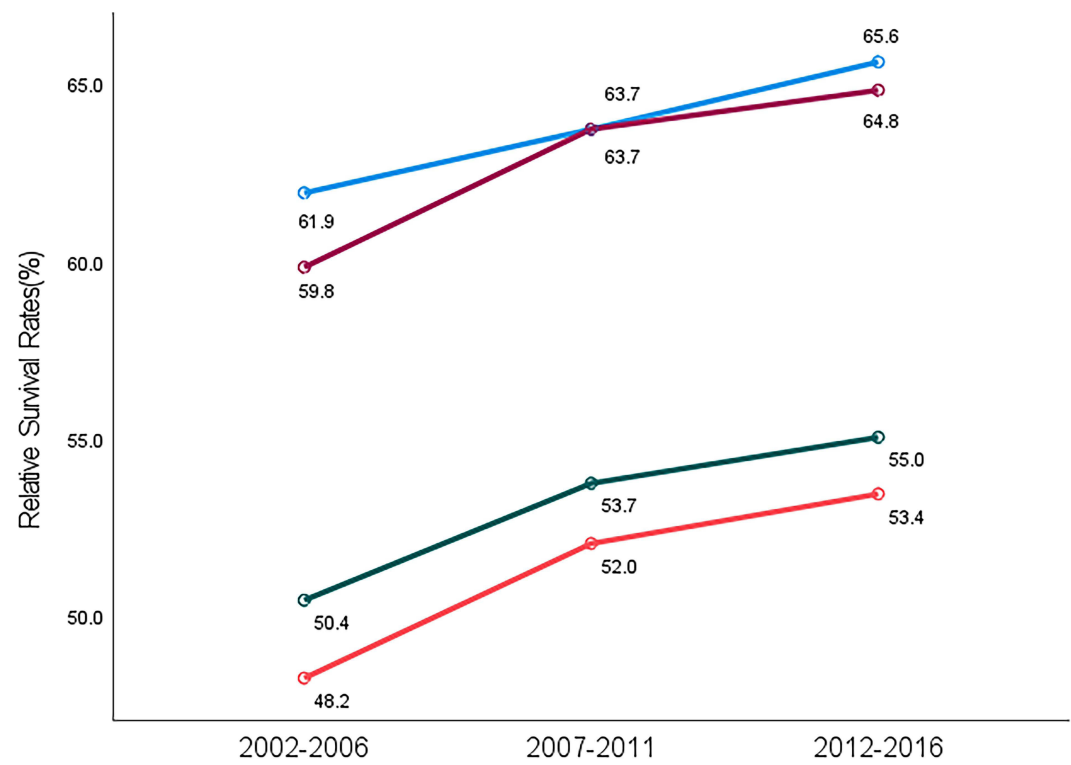

$\bigcirc$ Female(3-year)

-Female(5-year)

-Male(3-year)

Male(5-year)

Figure 2 Trend and prediction of survival rate in patients with cecal adenocarcinoma of different genders.

of patients with right colon cancer is worse than that of patients with left colon cancer. ${ }^{18}$

In the present study, the vast majority of people $(>90 \%)$ are 50 years old. Older patients account for a large proportion, indicating that similar to traditional colorectal cancer, the difference in age distribution has an important effect on survival. ${ }^{17}$ Studies showed that the survival rate of colorectal cancer decreases with age. ${ }^{19}$ In the present study, the survival rate of cecal adenocarcinoma decreases with age, especially at age more than 75 years. This finding may be related to postoperative complications in elderly patients with cecal adenocarcinoma. The postoperative complications of colorectal cancer often have a negative effect on the survival rate of patients. $^{20,21}$ The 3- and 5-year survival rates of patients with cecal adenocarcinoma increase gradually during the three observation periods and may benefit from advances in insurance plans and screening methods. ${ }^{22}$ The insurance plan includes the popularity of colonoscopy, which helps enable tumors to be detected at an early stage. ${ }^{23}$ In recent years, the intubation technology has been continuously improved, which is important for improving the protection of the right colon cancer in the elderly. ${ }^{22,24}$ 
Table 3 3-Year and 5-Year Relative Survival Rates of Cecal Adenocarcinoma Patients According to Race and Socioeconomic Status from 2002 to 2016 and Forecast of the Relative Survival Rates of Cecal Adenocarcinoma Patients According to Race and Socioeconomic Status from 2017 to 2021

\begin{tabular}{|l|l|l|l|l|}
\hline & $\begin{array}{l}\text { 2002- } \\
\text { 2006 }\end{array}$ & $\begin{array}{l}\text { 2007- } \\
\mathbf{2 0 I I}\end{array}$ & $\begin{array}{l}\mathbf{2 0 1 2 -} \\
\mathbf{2 0 1 6}\end{array}$ & $\begin{array}{l}\mathbf{2 0 1 7 -} \\
\mathbf{2 0 2 1}\end{array}$ \\
\hline 3 years survival rates & & & & \\
White & $61.4 \pm 0.4$ & $64.0 \pm 0.4$ & $65.6 \pm 0.4$ & 66.70 \\
Black & $55.5 \pm 1.0$ & $60.6 \pm 0.9$ & $62.3 \pm 0.9$ & 63.99 \\
Other races & $65.3 \pm 1.5$ & $66.7 \pm 1.4$ & $67.6 \pm 1.4$ & 69.46 \\
Rich & $61.6 \pm 1.3$ & $64.3 \pm 1.3$ & $67.9 \pm 1.3$ & 69.97 \\
Low poverty & $62.3 \pm 0.7$ & $65.3 \pm 0.7$ & $66.8 \pm 0.7$ & 69.27 \\
Medium poverty & $61.5 \pm 0.6$ & $63.9 \pm 0.6$ & $65.9 \pm 0.6$ & 66.85 \\
High poverty & $59.3 \pm 0.6$ & $62.3 \pm 0.6$ & $63.2 \pm 0.6$ & 63.85 \\
\hline 5 years survival rates & & & & \\
White & $49.7 \pm 0.4$ & $53.0 \pm 0.4$ & $54.5 \pm 0.4$ & 57.24 \\
Black & $44.9 \pm 1.1$ & $50.2 \pm 1.0$ & $50.9 \pm 1.0$ & 54.87 \\
Other races & $55.9 \pm 1.7$ & $57.4 \pm 1.5$ & $59.6 \pm 1.4$ & 61.28 \\
Rich & $50.1 \pm 1.4$ & $51.9 \pm 1.4$ & $57.8 \pm 1.4$ & 61.28 \\
Low poverty & $50.8 \pm 0.7$ & $54.6 \pm 0.7$ & $57.1 \pm 0.7$ & 60.82 \\
Medium poverty & $49.7 \pm 0.6$ & $53.1 \pm 0.6$ & $54.2 \pm 0.6$ & 56.98 \\
High poverty & $48.1 \pm 0.6$ & $51.1 \pm 0.6$ & $51.8 \pm 0.6$ & 54.29 \\
\hline
\end{tabular}

Note: Survival rates is relative survival rates; data are means \pm standard error of the mean.

In this study, the proportion of cecal adenocarcinoma between 2002 and 2016 of women and man is about $1.23: 1$, which is similar to the above report. This finding suggests that the effect of gender on the survival rate of patients with cecal adenocarcinoma should be paid attention. In several reports, the survival rate of male patients with cecal adenocarcinoma is lower than that of female patients. $^{25,26}$ In this study, we can observe that the 3-and 5-year survival rates of men are lower than those of women, which may be related to the differences in living habits between the two sexes. Men are more likely to eat too much red meat than women. In addition, smoking, drinking, and other bad habits are more common among men than among women. These factors increase the incidence of colorectal cancer. ${ }^{27}$ Some studies also pointed out that different hormone levels in men and women have different degrees of influence in different age groups of both sexes. $^{28,29}$ The survival rates of male and female patients with cecal adenocarcinoma increase gradually from 2002 to 2016. This finding may be related to the popularity of colonoscopy screening and advances in medical science and technology.

Results show that the survival rates of other races and whites are higher than those of black people. Other races, including Asians and Indians, are difficult to analyze. Studies pointed out that the differences between blacks and whites are related to a variety of factors, such as socioeconomic status, health insurance, screening, and

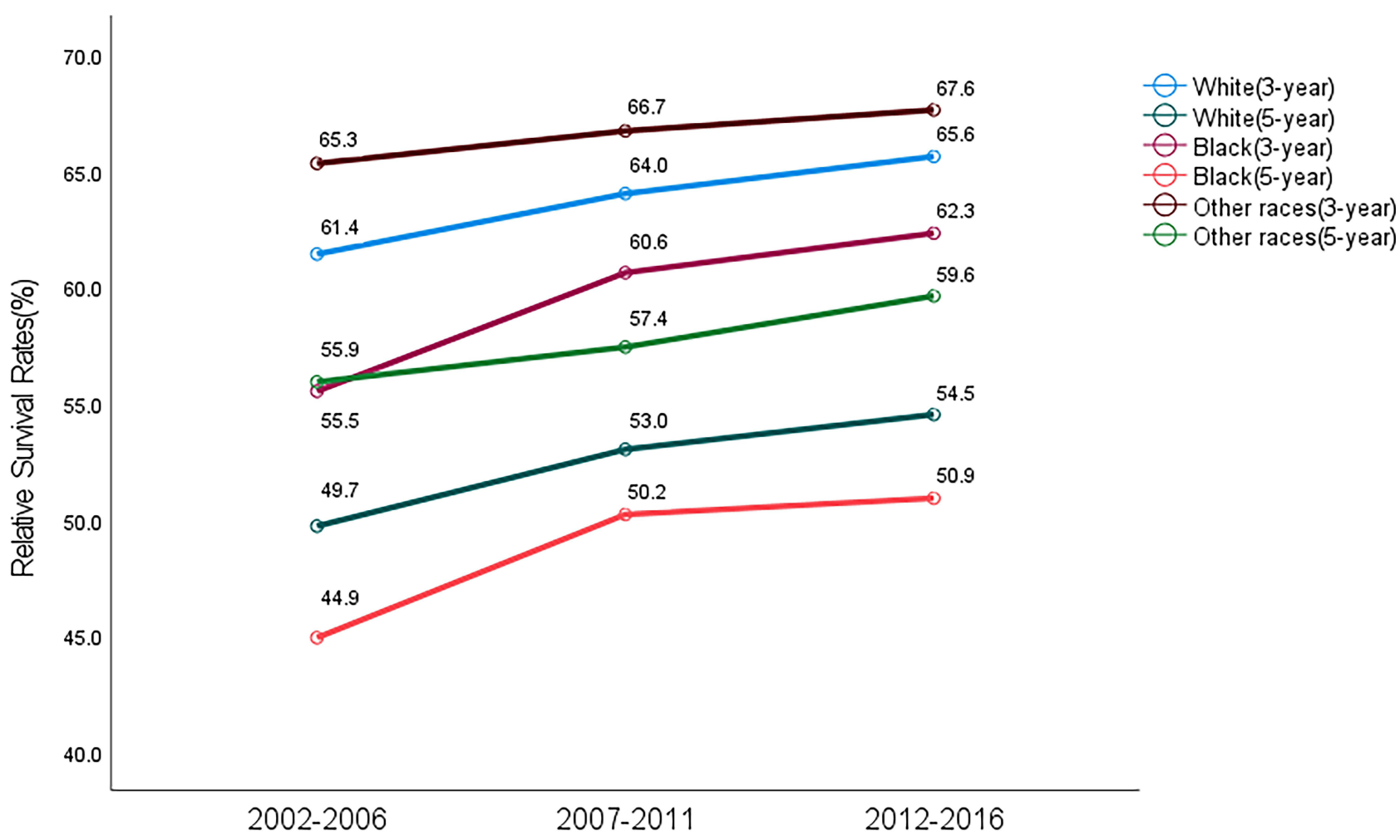

Figure 3 Trend and prediction of survival rate in patients with cecal adenocarcinoma of different races. 


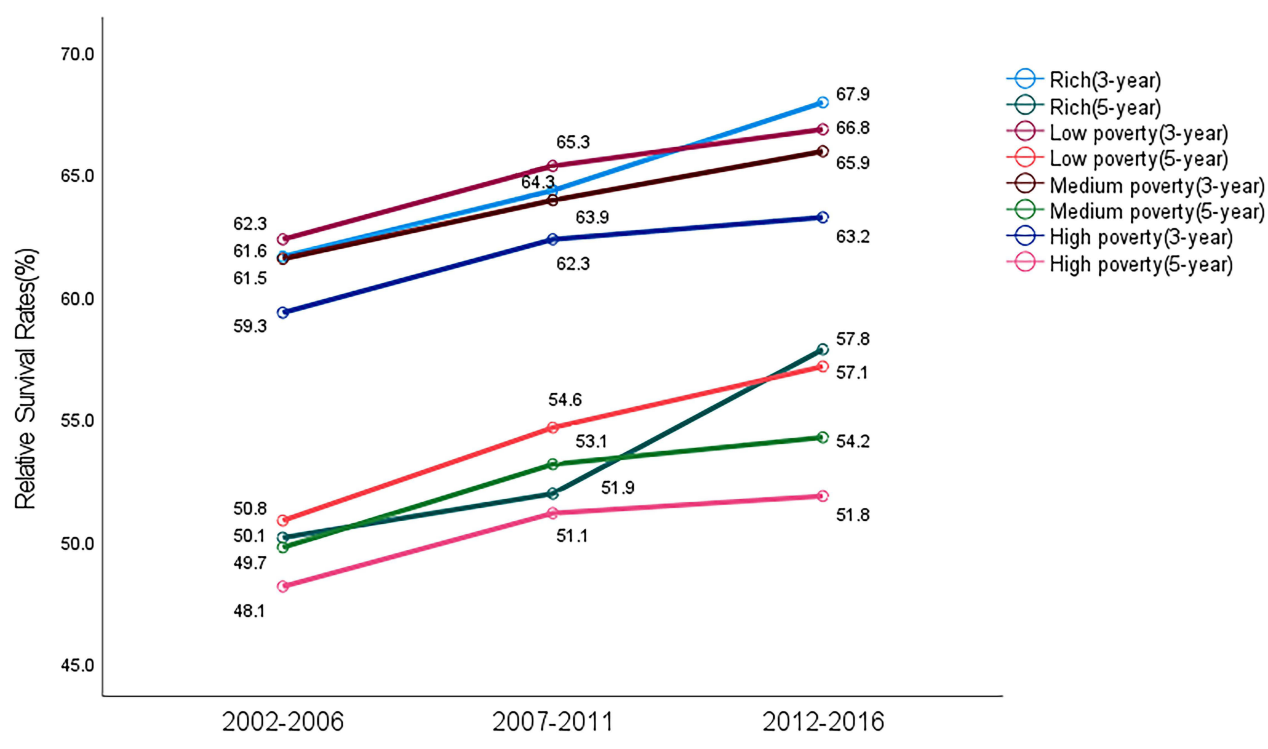

Figure 4 Trend and prediction of survival rate in patients with cecal adenocarcinoma of different socioeconomic statuses.

complications. $^{30}$ In the analysis of the national cancer database data, the difference in insurance coverage accounts for about half of the difference in survival rates between black and white patients with colorectal cancer and between the ages of 18 and $64 .{ }^{31}$ Providing affordable health insurance for all can remarkably reduce the difference in survival time between black and white patients with colorectal cancer. Results show that survival rates

Table 4 3-Year and 5-Year Relative Survival Rates of Cecal Adenocarcinoma Patients According to Differentiation Grade and Stage from 2002 to 2016 and Forecast of the Relative Survival Rates of Cecal Adenocarcinoma Patients According to Differentiation Grade from 2017 to 2021

\begin{tabular}{|l|l|l|l|l|}
\hline & $\begin{array}{l}2002- \\
2006\end{array}$ & $\begin{array}{l}2007- \\
201 \text { I }\end{array}$ & $\begin{array}{l}2012- \\
2016\end{array}$ & $\begin{array}{l}\text { 20I7- } \\
202 I\end{array}$ \\
\hline Y years survival rates & & & & \\
GI/G2 & $65.2 \pm 0.4$ & $67.9 \pm 0.4$ & $69.5 \pm 0.4$ & 71.34 \\
G3/G4 & $48.0 \pm 0.7$ & $50.5 \pm 0.7$ & $50.8 \pm 0.7$ & 50.76 \\
Localized & $79.3 \pm 0.4$ & $81.3 \pm 0.4$ & $82.9 \pm 0.4$ & 84.33 \\
Regional & $63.9 \pm 0.5$ & $66.0 \pm 0.5$ & $67.9 \pm 0.5$ & 69.68 \\
Distant & $15.2 \pm 0.6$ & $20.4 \pm 0.6$ & $22.5 \pm 0.7$ & 25.07 \\
\hline 5 years survival rates & & & & \\
GI/G2 & $52.8 \pm 0.4$ & $56.7 \pm 0.4$ & $58.1 \pm 0.4$ & 61.38 \\
G3/G4 & $39.1 \pm 0.7$ & $41.0 \pm 0.7$ & $41.5 \pm 0.7$ & 42.72 \\
Localized & $67.6 \pm 0.6$ & $70.9 \pm 0.5$ & $72.8 \pm 0.5$ & 75.93 \\
Regional & $50.9 \pm 0.5$ & $54.1 \pm 0.5$ & $55.7 \pm 0.5$ & 58.53 \\
Distant & $7.6 \pm 0.5$ & $10.5 \pm 0.5$ & $12.0 \pm 0.5$ & 15.11 \\
\hline
\end{tabular}

Note: Survival rates is relative survival rates; data are means \pm standard error of the mean. among different races increase steadily over time and approach one another, which may be due to increased technology and popularity of colorectal cancer screening. 32,33

From 2002 to 2016, the survival rates of people at all socioeconomic status increase, showing that the 3- and 5 -year survival rates decrease with increased poverty in the area where the family is located. However, results show that the survival rates of patients from high-income areas are lower than those of patients from poor areas in 2002-2006 until 2012-2016. This result may be because at the beginning of the 20th century, high-income people are diagnosed with advanced cecal adenocarcinoma, whereas many poor people with advanced cecal adenocarcinoma are not tested. This result is due to the limitation of insurance coverage at that time. ${ }^{33}$ As a result, the mortality rate of patients from wealthy areas is low in 2002-2006. Low-income families rely on health insurance and other government welfare policies. The poor quality of housing welfare services often affects their mental health and increases the prevalence of depression. ${ }^{34}$ Depression can generally be considered a major cause of cancer. ${ }^{35}$ Regardless of the socioeconomic status, the survival rate of patients has also been greatly improved. A Canadian census shows a similar trend. ${ }^{36}$ In addition, a New Zealand study based on income groups and cancer survival rates shows persistent racial inequality in the vitality of cancer villages over time and slow improvement among lowincome people. $^{37}$ 


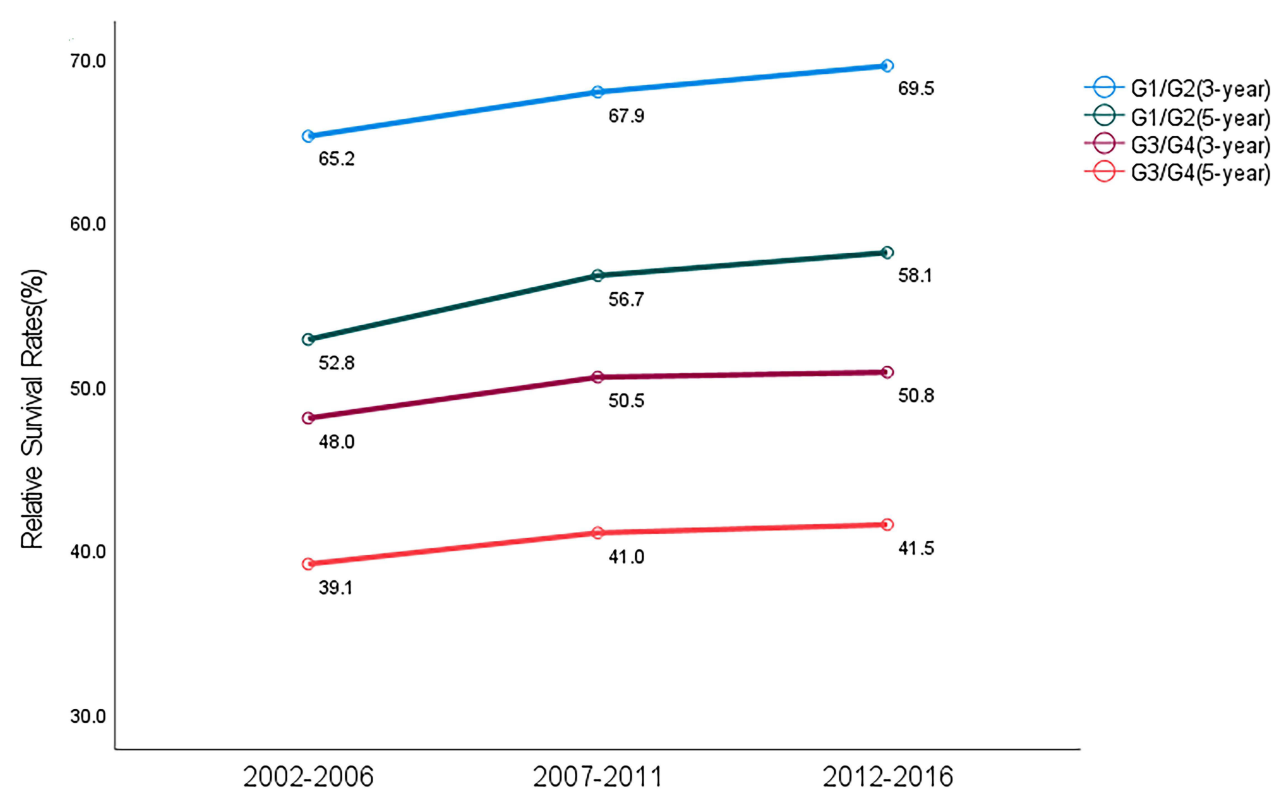

Figure 5 Trend and prediction of survival rate in patients with cecal adenocarcinoma of different grades.

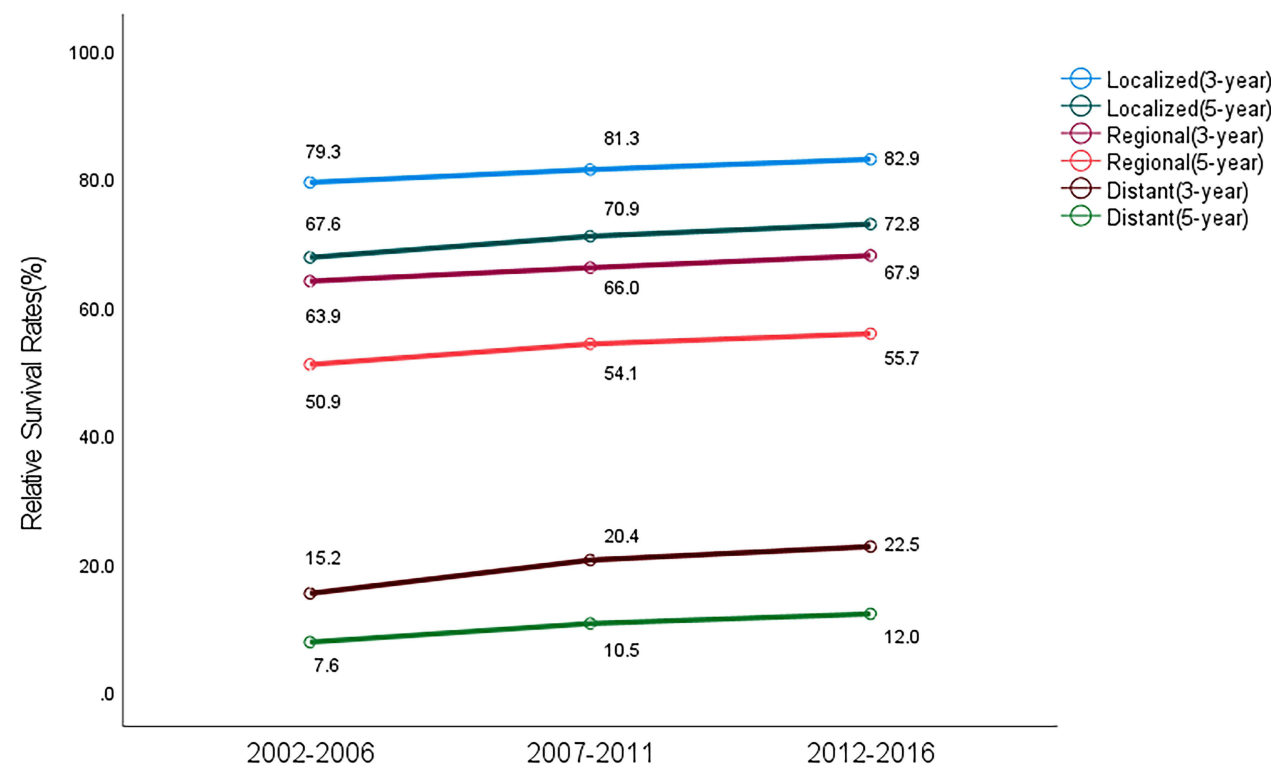

Figure 6 Trend and prediction of survival rate in patients with cecal adenocarcinoma of different stages.

At present, a high differentiation grade is one of the adverse histopathological factors related to the adverse clinical process of colorectal cancer. ${ }^{38}$ From 2002 to 2016, the survival rate of patients regardless of differentiation grade basically increases with time. Considering the diversity of methods used to evaluate differentiation grade and the instability caused by the subjectivity of such assessments. ${ }^{39}$ Grade was divided into two groups: grade I and II and grade III and IV. Differentiation grade is commonly evaluated through the percentage of glandular differentiation in tumors in accordance with the World Health Organization criteria. However, this grading system is affected by differences in evaluators and does not apply to some rare histological types of colorectal adenocarcinoma, such as micropapillary, mucinous, and signet ring cell variants. Therefore, considering the relatively few samples of grade IV cecal adenocarcinoma, the difference of pathological typing between grades III and IV cecal adenocarcinoma is remarkably reduced. The results of this study showed that the 3-and 5-year survival rates of 
patients with cecal adenocarcinoma in grade III and IV were more than ten percentage points lower than those in grade I and II. However, the trend that the survival rate of patients regardless of differentiation grade is increasing cannot be denied.

Disease staging is very important for treatment planning and evaluating prognosis. No matter which staging method is used, SEER Summary Stage 2000 can correspond to it. The results showed that the vast majority of patients with cecal adenocarcinoma were in localizedstage and regional-stage, while the number of patients with distant-stage was small. Of these, about half of colorectal cancers are diagnosed in regional-stage and distantstage. ${ }^{40}$ Some studies have pointed out that with the improvement of socioeconomic status and family income, the number and risk of colorectal cancer diagnosis in distant-stage decreased significantly. In terms of racial differences, black patients had the highest number of colorectal cancer diagnosed with distant-stage. ${ }^{41}$ This may explain the lowest 3 -and 5-year survival rates for blacks in this study.

With the passage of time, the prognosis of cecal adenocarcinoma has been greatly improved. The improvement of survival rate and prognosis are closely related to the progress of screening methods. Microsatellite analysis is an effective tool for screening colorectal cancer. By evaluating the occurrence of microsatellite instability (MSI-H), we can detect the location of colorectal cancer and stage. ${ }^{42}$ Importantly, using the revised Bethesda guidelines, the expansion of which to include patients with right colon cancer can significantly reduce the probability of omission in patients with MSI$\mathrm{H}^{43}$ At the same time, colorectal cancer with MSI-H is mainly located on the right side and has an early pathological stage. ${ }^{42}$ Since then, the probability of cecal adenocarcinoma in the early pathological stage increased when it was found. As a result, the prognosis and survival rate of cecal adenocarcinoma can be greatly improved. Compared with right-sided colon cancer, leftsided colon cancer has a better prognosis in the early pathological stage. Because MSI is mainly found in right-sided colon cancer (about $25 \%$ ), ${ }^{44}$ while $<5 \%$ is seen in left-sided colon cancer. ${ }^{45}$

\section{Limitations}

Some limitations are present in this study. (1) The registration of the SEER database completely depends on the conditions of provider diagnosis and recording.
Underdiagnosed or asymptomatic cancer may lead to reduced number of confirmed cases. (2) The SEER database no longer provides information on the use of radiotherapy and chemotherapy. Thus, the link between changed treatment and improved survival outcomes is difficult to assess directly. (3) Through the above analysis, we can find that there are significant differences in the survival rate of cecal adenocarcinoma among different races. People of different races, even the same race in different regions, have different living habits. And SEER often combines several other races into one group, which makes it difficult for us to analyze a area with a single race. The results of this study only reflect parts of the United States and do not apply to other geographical locations.

\section{Conclusion}

Overall, our SEER-based analysis shows that the relative survival rate of patients with cecal adenocarcinoma has changed remarkably over the past 15 years. However, the overall relative survival rate of patients with cecal adenocarcinoma remains low. The changing trend of survival rate shows that the differences between races decreases over time, whereas the differences between different socioeconomic status are increasing. It is worth noting that the 3-and 5-year survival rates of cecal adenocarcinoma in regional-stage and distantstage are very low. Understanding the survival rate of patients with cecal adenocarcinoma in the past 15 years is helpful in predicting future trends and preventing and treating cecal adenocarcinoma by exploring the differences in survival rate corresponding to different ages, sexes, races, differentiation grades, and socioeconomic status.

\section{Data Sharing Statement}

The data sets generated and/or analyzed during the current study are available in the SEER database (https://seer. cancer.gov/).

\section{Author Contributions}

All authors made a significant contribution to the work reported, whether that is in the conception, study design, execution, acquisition of data, analysis and interpretation, or in all these areas; took part in drafting, revising or critically reviewing the article; gave final approval of the version to be published; have agreed on the journal to 
which the article has been submitted; and agree to be accountable for all aspects of the work.

\section{Disclosure}

The authors have no conflicts of interest to declare.

\section{References}

1. Siegel RL, Miller KD, Goding Sauer A, et al. Colorectal cancer statistics, 2020. CA Cancer J Clin. 2020;70(3):145-164. doi:10.3322/caac. 21601

2. Haraldsdottir S, Einarsdottir HM, Smaradottir A, Gunnlaugsson A, Halfdanarson TR. [Colorectal cancer - review] Krabbamein i ristli og endathornarmi. Laeknabladid. 2014;100(2):75-82. doi:10.17992/ $1 b 1.2014 .02 .531$

3. Wu W, Yang J, Li D, et al. Competitive risk analysis of prognosis in patients with cecum cancer: a population-based study. Cancer Control. 2021;28:1073274821989316. doi:10.1177/10732748219 89316

4. Liang PS, Mayer JD, Wakefield J, et al. Trends in sociodemographic disparities in colorectal cancer staging and survival: a SEER-medicare analysis. Clin Transl Gastroenterol. 2020;11(3): e00155. doi:10.14309/ctg.0000000000000155

5. Kolligs FT. Diagnostics and epidemiology of colorectal cancer. Visc Med. 2016;32(3):158-164. doi:10.1159/000446488

6. Hermann J, Karmelita-Katulska K, Paszkowski J, Drews M, Stajgis M. Diagnosis of a cecal tumour with virtual colonoscopy. Pol J Radiol. 2011;76(2):25-27.

7. Moritani K, Hasegawa H, Okabayashi K, Ishii Y, Endo T, Kitagawa $Y$. Difference in the recurrence rate between right- and left-sided colon cancer: a 17-year experience at a single institution. Surg Today. 2014;44(9):1685-1691. doi:10.1007/s00595-013-0748-5

8. Wu W-T, Li Y-J, Feng A-Z, et al. Data mining in clinical big data: the frequently used databases, steps, and methodological models. Mil Med Res. 2021;8(1). doi:10.1186/s40779-021-00338-z

9. Yang J, Li Y, Liu Q, et al. Brief introduction of medical database and data mining technology in big data era. J Evid Based Med. 2020;13 (1):57-69. doi:10.1111/jebm.12373

10. Henson DE, Ries LA. The relative survival rate. Cancer. 1995;76 (10):1687-1688. doi:10.1002/1097-0142(19951115)76:10<687::aidcncr2820761002>3.0.co;2-i

11. Ederer F, Axtell LM, Cutler SJ. The relative survival rate: a statistical methodology. Natl Cancer Inst Monogr. 1961;6:101-121.

12. Parkin DM, Hakulinen T. Cancer registration: principles and methods. Analysis of survival. IARC Sci Publ. 1991;95:159-176.

13. Center for Disease Control and Prevention. Life tables[DB/OL]; 2021:7-20. Available from: https://www.cdc.gov/nchs/products/life_ table.htm. Accessed June 11, 2021.

14. Meguid RA, Slidell MB, Wolfgang CL, Chang DC, Ahuja N. Is there a difference in survival between right- versus left-sided colon cancers? Ann Surg Oncol. 2008;15(9):2388-2394. doi:10.1245/ s10434-008-0015-y

15. Xie X, Zhou Z, Song Y, Wang W, Dang C, Zhang H. Differences between carcinoma of the cecum and ascending colon: evidence based on clinical and embryological data. Int J Oncol. 2018;53 (1):87-98. doi:10.3892/ijo.2018.4366

16. Benedix F, Kube R, Meyer F, et al. Comparison of 17,641 patients with right- and left-sided colon cancer: differences in epidemiology, perioperative course, histology, and survival. Dis Colon Rectum. 2010;53(1):57-64. doi:10.1007/DCR.0b013e3181c703a4

17. Warschkow R, Sulz MC, Marti L, et al. Better survival in right-sided versus left-sided stage I - III colon cancer patients. BMC Cancer. 2016;16:554. doi:10.1186/s12885-016-2412-0
18. Hansen IO, Jess P. Possible better long-term survival in left versus right-sided colon cancer - a systematic review. Dan Med J. 2012;59 (6):A4444.

19. Cook AD, Single R, McCahill LE. Surgical resection of primary tumors in patients who present with stage IV colorectal cancer: an analysis of surveillance, epidemiology, and end results data, 1988 to 2000. Ann Surg Oncol. 2005;12(8):637-645. doi:10.1245/ASO.20 05.06.012

20. Hashimoto S, Hamada K, Sumida Y, et al. Postoperative complications predict long-term outcome after curative resection for perforated colorectal cancer. In Vivo (Brooklyn). 2021;35(1):555-561. doi:10.21873/invivo.12291

21. Miyamoto Y, Hiyoshi Y, Tokunaga R, et al. Postoperative complications are associated with poor survival outcome after curative resection for colorectal cancer: a propensity-score analysis. J Surg Oncol. 2020;122(2):344-349. doi:10.1002/jso.25961

22. Yang L, Liu S, Xiong Z, et al. Changes in colorectal cancer incidence by site and age from 1973 to 2015: a SEER database analysis. Aging Clin Exp Res. 2021;33(7):1937-1946. doi:10.1007/s40520-02001721-x

23. Austin PC, Lee DS, Fine JP. Introduction to the analysis of survival data in the presence of competing risks. Circulation. 2016;133 (6):601-609. doi:10.1161/CIRCULATIONAHA.115.017719

24. Berry SD, Ngo L, Samelson EJ, Kiel DP. Competing risk of death: an important consideration in studies of older adults. $J$ Am Geriatr Soc. 2010;58(4):783-787. doi:10.1111/j.1532-5415.2010.02767.x

25. Weiss JM, Pfau PR, O'Connor ES, et al. Mortality by stage for rightversus left-sided colon cancer: analysis of surveillance, epidemiology, and end results-Medicare data. J Clin Oncol. 2011;29 (33):4401-4409. doi:10.1200/JCO.2011.36.4414

26. Wang W, Chen W, Lin J, Shen Q, Zhou X, Lin C. Incidence and characteristics of young-onset colorectal cancer in the United States: an analysis of SEER data collected from 1988 to 2013. Clin Res Hepatol Gastroenterol. 2019;43(2):208-215. doi:10.1016/j. clinre.2018.09.003

27. Bradbury KE, Murphy N, Key TJ. Diet and colorectal cancer in UK Biobank: a prospective study. Int J Epidemiol. 2020;49(1):246-258. doi:10.1093/ije/dyz064

28. Marjoribanks J, Farquhar C, Roberts H, Lethaby A, Lee J. Long-term hormone therapy for perimenopausal and postmenopausal women. Cochrane Database Syst Rev. 2017;1:CD004143. doi:10.1002/ 14651858.CD004143.pub5

29. Li S, Chen Y, Xie L, et al. Sex hormones and genetic variants in hormone metabolic pathways associated with the risk of colorectal cancer. Environ Int. 2020;137:105543. doi:10.1016/j. envint.2020.105543

30. Galadima HI, Adunlin G, Hughes MS, Cropp CD, Lucero L, Akpinar-Elci M. Racial disparities and treatment trends among young-onset colorectal cancer patients: an analysis of a hospital cancer registry. Cancer Epidemiol. 2021;72:101911. doi:10.1016/j. canep.2021.101911

31. Sineshaw HM, Ng K, Flanders WD, Brawley OW, Jemal A. Factors that contribute to differences in survival of black vs white patients with colorectal cancer. Gastroenterology. 2018;154(4):906-915 e7. doi:10.1053/j.gastro.2017.11.005

32. Lund M, Trads M, Njor SH, Erichsen R, Andersen B. Quality indicators for screening colonoscopy and colonoscopist performance and the subsequent risk of interval colorectal cancer: a systematic review. JBI Database System Rev Implement Rep. 2019;17 (11):2265-2300. doi:10.11124/JBISRIR-2017-003927

33. Warren Andersen S, Blot WJ, Lipworth L, Steinwandel M, Murff HJ, Zheng W. Association of race and socioeconomic status with colorectal cancer screening, colorectal cancer risk, and mortality in southern US adults. JAMA Netw Open. 2019;2(12):e1917995. doi:10.1001/ jamanetworkopen.2019.17995 
34. Park K, Seo W. Effects of residential instability of renters on their perceived health status: findings from the Korean welfare panel study. Int J Environ Res Public Health. 2020;17(19). doi:10.3390/ ijerph17197125

35. Pinquart M, Duberstein PR. Depression and cancer mortality: a meta-analysis. Psychol Med. 2010;40(11):1797-1810. doi:10.1017/ S0033291709992285

36. Shahidi FV, Parnia A, Siddiqi A. Trends in socioeconomic inequalities in premature and avoidable mortality in Canada, 1991-2016. CMAJ. 2020;192(39):E1114-E1128. doi:10.1503/cmaj.191723

37. Soeberg M, Blakely T, Sarfati D. Trends in ethnic and socioeconomic inequalities in cancer survival, New Zealand, 1991-2004. Cancer Epidemiol. 2015;39(6):860-862. doi:10.1016/j.canep.2015.10.018

38. Barresi V, Reggiani Bonetti L, Ieni A, Caruso RA, Tuccari G. Histological grading in colorectal cancer: new insights and perspectives. Histol Histopathol. 2015;30(9):1059-1067. doi:10.14670/HH-11-633

39. Marzouk O, Schofield J. Review of histopathological and molecular prognostic features in colorectal cancer. Cancers. 2011;3 (2):2767-2810. doi:10.3390/cancers3022767

40. Bryan S, Masoud H, Weir HK, et al. Cancer in Canada: stage at diagnosis. Health Rep. 2018;29(12):21-25.
41. Clegg LX, Reichman ME, Miller BA, et al. Impact of socioeconomic status on cancer incidence and stage at diagnosis: selected findings from the surveillance, epidemiology, and end results: national Longitudinal Mortality Study. Cancer Causes Control. 2009;20 (4):417-435. doi:10.1007/s10552-008-9256-0

42. Chou CL, Lin JK, Wang HS, Yang SH, Li AF, Chang SC. Microsatellite instability screening should be done for right-sided colon cancer patients less than 60 years of age. Int $J$ Colorectal Dis. 2010;25(1):47-52. doi:10.1007/s00384-009-0815-y

43. Urso E, Pucciarelli S, Agostini M, et al. Proximal colon cancer in patients aged 51-60 years of age should be tested for microsatellites instability. A comment on the Revised Bethesda Guidelines. Int J Colorectal Dis. 2008;23(8):801-806. doi:10.1007/s00384-0080484-2

44. Gervaz P, Bucher P, Morel P. Two colons-two cancers: paradigm shift and clinical implications. J Surg Oncol. 2004;88(4):261-266. doi:10.1002/jso.20156

45. Iacopetta B. Are there two sides to colorectal cancer? Int J Cancer. 2002;101(5):403-408. doi:10.1002/ijc.10635
International Journal of General Medicine

\section{Publish your work in this journal}

The International Journal of General Medicine is an international, peer-reviewed open-access journal that focuses on general and internal medicine, pathogenesis, epidemiology, diagnosis, monitoring and treatment protocols. The journal is characterized by the rapid reporting of reviews, original research and clinical studies
Dovepress

across all disease areas. The manuscript management system is completely online and includes a very quick and fair peer-review system, which is all easy to use. Visit http://www.dovepress.com/ testimonials.php to read real quotes from published authors. 